\title{
Forecasting the impact on the environment of generating sources in agricultural production
}

\author{
E. Timofeev, and A. Erk
}

Federal State Budgetary Scientific Institution 'Federal Scientific Agroengineering Center VIM', branch in Saint Petersburg, Filtrovskoje highway, 3 p.o. Tiarlevo, 196625 Saint Petersburg, Russia

\begin{abstract}
The development of rural electrification is aimed at distributed energy, i.e. availability of autonomous sources of electricity and heat generation. Generation sources can use coal, fuel oil, gas, local and alternative energy sources as fuel and energy resources. This causes additional emissions of pollutants. Prediction of negative impact on the environment depends on the quantity and quality of emissions during the operation of various types of installations that generate electric and thermal energy. The purpose of the study is to select and substantiate the most attractive method for predicting the impact on the environment of generating sources in agricultural production. The widespread introduction of distributed energy using local and renewable energy sources will significantly reduce emissions of pollutants due to a decrease in energy intensity, matching the required load with the capacity of generation sources, using the most energy efficient sources, and widespread introduction of renewable energy sources. In this regard, it is advisable to forecast the impacts by the scenario method considering the implementation of the proposed distributed power supply system. The implementation of measures developed considering the analysis of the forecast of the negative impact on the environment of generating plants in agricultural enterprises will reduce the negative impact on the environment by introducing energy-efficient technologies into the energy balance of the enterprise, as well as increase production by up to $20 \%$ and increase sustainability. rural areas.
\end{abstract}

\section{Introduction}

The structure of consumption of fuel and energy resources (FER) in agricultural production of the Leningrad region of the Russian Federation is shown in Figures 1, 2, 3 [1,2]. 


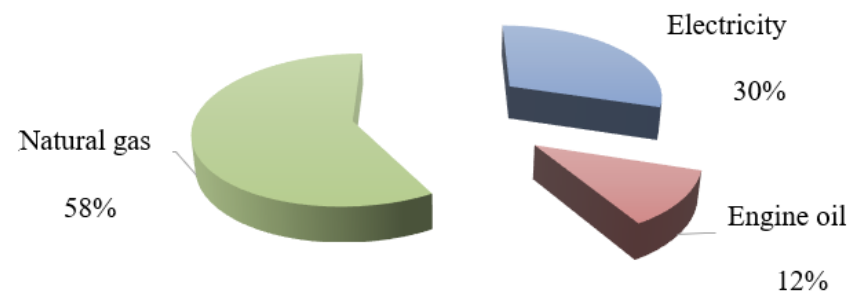

Fig. 1. Energy consumption by poultry enterprises.

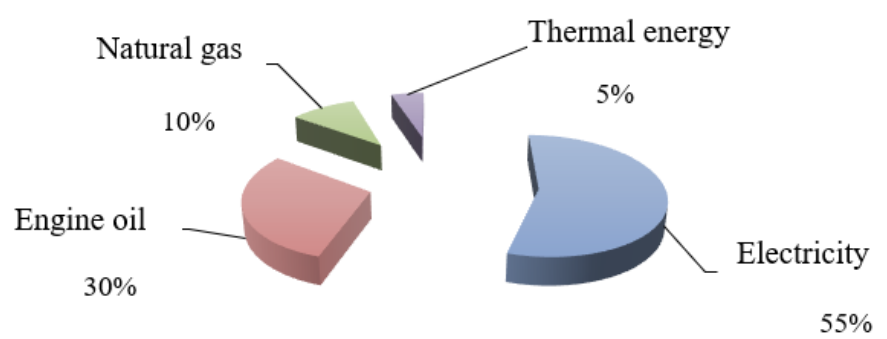

Fig. 2. Energy consumption by pig farms.

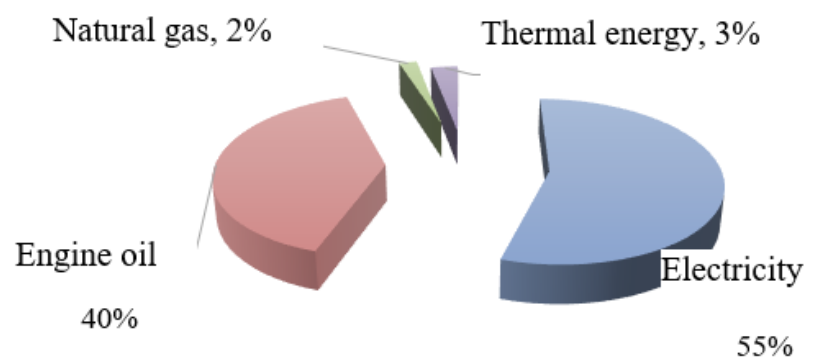

Fig. 3. Energy consumption of dairy livestock enterprises.

Electricity consumption ranges from 30 to $55 \%$. Currently, the centralized power supply system is mainly used. However, the development of rural electrification is aimed at distributed energy $[3,4,5]$, i.e. availability of autonomous sources of electricity and heat generation. Generation sources can use coal, fuel oil, gas, local and alternative energy sources as fuel and energy resources. This causes additional emissions of pollutants.

Prediction of negative impact on the environment depends on the quantity and quality of emissions during the operation of installations of various types that generate electrical and thermal energy $[6,7]$.

The aim of the study is: selection and justification of the most attractive method for predicting the negative impact on the environment of generating sources in agricultural production.

\section{Materials and methods}

The analysis is based on the results of energy audits of farms in the Leningrad region, conducted by the Institute from 2011 to the present. Also, express surveys of five farms, conducted by the survey method in 1Q 2020. 
Of particular interest in the express survey was the question of the availability of autonomous sources of generation using both traditional and renewable energy sources. Table 1 presents the initial data for calculating the negative impact on the environment.

Table 1. Initial data of indicators for farms for predicting the impact

\begin{tabular}{|c|c|c|c|c|}
\hline \multirow{2}{*}{ Name of indicators } & \multicolumn{4}{|c|}{ Years } \\
\cline { 2 - 5 } & 2014 & 2015 & 2017 & 2018 \\
\hline \multicolumn{5}{|c|}{ Household 1 } \\
\hline Production value, RUR & 101594 & 139903 & 133615 & 182388 \\
\hline FER consumption, c.f.t. & 1679 & 1711 & 1652 & 1819 \\
\hline \multicolumn{5}{|c|}{ Household 2 } \\
\hline Production value, RUR & 241462 & 250974 & 315364 & 336694 \\
\hline FER consumption, c.f.t. & 2830.8 & 2666.7 & 2607.1 & 2544.6 \\
\hline \multicolumn{5}{|c|}{ Household 3 } \\
\hline Production value, RUR & 93811 & 98195 & 114325 & 147337 \\
\hline FER consumption, c.f.t. & $1,289.4$ & 1187.7 & 1284.3 & 1194.5 \\
\hline \multicolumn{5}{|c|}{ Household 4 } \\
\hline Production value, RUR & 52531 & 64984 & 86663 & 106370 \\
\hline FER consumption, c.f.t. & 1147.7 & 1246 & 1503.8 & 1472 \\
\hline \multicolumn{5}{|c|}{ Household 5 } \\
\hline Production value, RUR & 52531 & 64984 & 86663 & 106370 \\
\hline FER consumption, c.f.t. & 1147.7 & 1246 & 1503.8 & 1472 \\
\hline
\end{tabular}

\section{Results and discussion}

Forecasting the negative impact on the environment from the operation of sources of electricity and heat generation in agricultural production.

Autonomous generation sources: boilers running on gas, wood, solid or liquid fuels, etc., are sources of environmental pollution due to emissions of combustion products. In addition, the operation of heat generators in drying plants is also accompanied by emissions.

Table 2. Levels of emissions of pollutants into the atmosphere when burning various types of fuel

\begin{tabular}{|l|l|l|l|l|l|l|}
\hline \multirow{2}{*}{ Fuel type } & \multicolumn{5}{|c|}{ Emissions of pollutants into the air, t per 1,000 t of nat. fuel } \\
\cline { 2 - 7 } & $\mathrm{CO}_{2}$ & $\mathrm{NO}_{2}$ & $\mathrm{SO}_{2}$ & Solid particles (inorganic dust) & TOTAL \\
\hline Natural gas & 1.18 & 3.52 & 0.00 & 0.00 & 4.70 \\
\hline Bituminous coal & 9.58 & 63.56 & 9.20 & 65.32 & 147.66 \\
\hline Fuel oil & 5.20 & 5.20 & 35.30 & 0.30 & 45.90 \\
\hline Peat briquette & 8.04 & 26.81 & 3.00 & 13.02 & 50.87 \\
\hline Wood briquettes, pellets & 4.68 & 9.31 & 0.28 & 4.11 & 17.69 \\
\hline Firewood & 4.9 & 9.4 & 0.3 & 4.3 & 18.9 \\
\hline Sawdust & 5.0 & 9.6 & 0.5 & 5.0 & 20.0 \\
\hline Waste wood, scraps & 5.2 & 9.9 & 0.4 & 5.2 & 20.7 \\
\hline Fast-growing wood & 4.8 & 9.5 & 0.0 & 8.4 & 22.7 \\
\hline Spill, boughs, bark & 5.6 & 11.4 & 0.8 & 13.4 & 31.3 \\
\hline
\end{tabular}

Table 2 shows that wood fuel (primarily pellets and briquettes) after natural gas is more preferable, from the point of view of air pollution, in comparison with fuel oil (especially with coal), since it has practically "zero effect" on greenhouse gas emissions. gases, primarily $\mathrm{CO} 2$. 
The results of energy surveys showed that at present, boiler houses for the generation of heat and electricity play an insignificant role in energy supply systems. Thus, the surveyed farms had and constantly applied: one boiler house on coal, two on fuel oil, eight on natural gas, four boilers on wood. On the other hand, almost all farms had 1-4 diesel generator sets to provide the first category of power supply to livestock farms during the period of a centralized power outage. The frequency of their activation was from 1 to ten times a year for a period of up to two days. In addition, the heat generators of the dryers operated during the harvesting period (two, three weeks) on liquid heating oil - fuel oil $[8,9,10]$.

In this regard, at present, forecasting the negative impact on the environment from the operation of sources of electricity and heat generation in agricultural production is difficult due to insufficient information.

The direction of development of rural energy is the widespread introduction of distributed energy using local and renewable energy sources. This will significantly reduce emissions of pollutants due to a decrease in energy intensity, matching the required load with the capacity of generation sources, using the most energy efficient sources, and widespread introduction of renewable energy sources $[11,12,13]$.

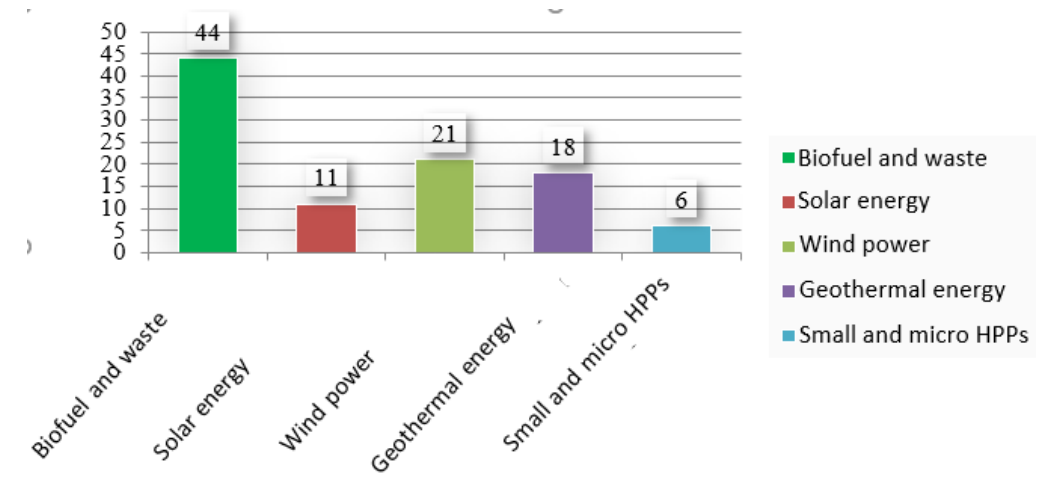

Fig. 4. The share of types of renewable energy sources in the distributed energy system.

In this regard, it is advisable to forecast the impacts by the scenario method considering the implementation of the proposed distributed power supply system.

The share of renewable energy sources in the agro-industrial complex is increasing every year and, pursuant to the forecast, by 2030, it will reach $25 \%$ in distributed energy networks [11]. Accordingly, emissions characterized by $\mathrm{CO} 2$ equivalent will be reduced by $21 \%$.

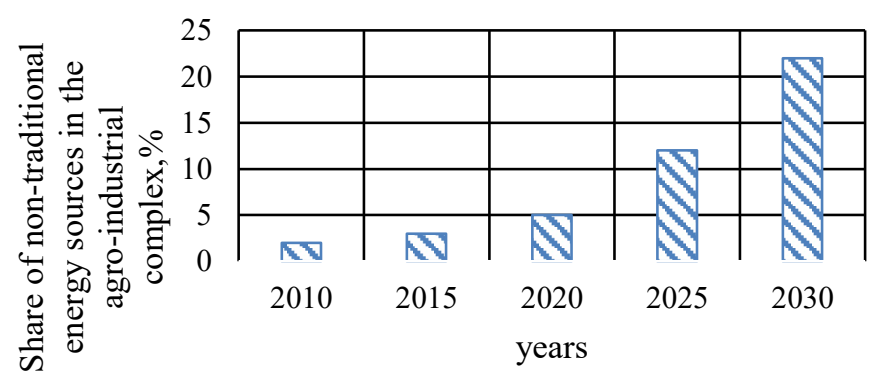

Fig. 5. Forecast of the development of the share of unconventional sources in the agro-industrial complex until 2030. 
As can be seen from the figure, the share of unconventional energy sources in the agroindustrial complex is growing rapidly and may reach $22 \%$ by 2030 .

\section{Conclusion}

1. The widespread introduction of distributed energy using local and renewable energy sources will significantly reduce emissions of pollutants due to a decrease in energy intensity, matching the required load with the capacity of generation sources, using the most energy efficient sources, and widespread introduction of renewable energy sources. In this regard, it is advisable to forecast the impacts by the scenario method considering the implementation of the proposed distributed power supply system.

2. The implementation of measures developed considering the analysis of the forecast of the negative impact on the environment of generating plants in agricultural enterprises will reduce the negative impact on the environment by introducing energy-efficient technologies into the energy balance of the enterprise, as well as increase production by up to $20 \%$ and increase sustainability. rural areas.

Testimonial.

A part of this work was performed within the framework of KS1675 project "RussianFinnish Bioeconomy Competence Centre - BioCom" of the "South-East Finland - Russia Cross-Border Cooperation (CBC) Programme 2014-2020”.

\section{References}

1. V. N. Brovtsin, A. F. Erk, O. V. Bychkova, Theoretical and scientific-practical journal "Mechanization and electrification of agriculture", 5, 22 (2014)

2. V. N. Sudachenko, A. F. Erk, E. V. Timofeev, Selection of energy supply option for agricultural production facilities pursuant to economic criteria, technologies and technical means of mechanized production of crop and livestock products, 92, 43 (2017)

3. A. V. Tikhomirov, M.: VIESH Bulletin., 1(22), 11 (2016)

4. A. V. Tikhomirov, I. I. Sventitsky, E. K. Markelova, V. Yu. Ukhanova, Energy strategy of agriculture in Russia for the period up to 2030, 75 (2015)

5. D. A. Tikhomirov, A. V. Tikhomirov, Agrotechnics and energy supply, 1(18), 47 (2018)

6. A. Shahsavari, M. Akbari, Renewable \& Sustainable Energy Reviews, 90, 275 (2018)

7. P. MacNaughton, X. Cao, J. Buonocore, J. Cedeno-Laurent, J. Spengler, A. Bernstein, J. Allen, Journal Of Exposure Science And Environmental Epidemiology, 28(4), 307 (2018)

8. A. F. Erk, V. N. Sudachenko, E. V. Timofeev, V. A. Razmuk, Technologies and technical means of mechanized production of crop and livestock products, 89, 19 (2016)

9. A. F. Erk, V. N. Sudachenko, E. V. Timofeev, V. A. Razmuk, Technologies and technical means of mechanized production of crop and livestock products, 1(94), 63 (2018)

10. A. F. Erk, V. N. Sudachenko, E. V. Timofeev, V. A. Razmuk, Technologies and technical means of mechanized production of crop and livestock products, 89, 23 (2016)

11. E.V. Shalavina, E.V. Vasilyev, Bulletin of APK Stavropol, 1(17), 366 (2015) 
12. C. Carnevale, F. Ferrari, G. Guariso, G. Maffeis, E. Turrini, M. Volta, Assessing the Economic and Environmental Sustainability of a Regional Air Quality Plan. Sustainability, 10(10) (2018)

13. M. N. Naz, N. Naeem, M. Iqbal, Journal of Renewable and Sustainable Energy, 9(1), (2017)

14. D. A. Tikhomirov, A.V. Tikhomirov, Electrotechnology and electrical equipment in the agro-industrial complex, 3(36), 3 (2019)

15. S. Ardebili, A. Khademalrasoul, Journal of Cleaner Production, 204, 819 (2018) 